\title{
20
}

\section{Private Childcare and Employment Options: The Geography of the Return to Work for Mothers in the Netherlands}

\author{
Tom Emery
}

In this chapter we examine the extent to which the return to work for mothers is affected by their proximity to various resources, facilities, and opportunities at the sub-regional level. Geocoded data from the Netherlands Kinship Panel Study (NKPS, waves 1-4, 2005-2014) are matched with geocoded data on childcare provision from administrative data, neighborhood level data on unemployment levels, and the proximity of individual's parents and other relatives who might act as childcare alternatives. The rich spatial data combined with a longitudinal approach enables the testing of a geographical perspective to women's employment. Crucially, the analysis looks at whether nurseries, childminders, or a mix of childcare institutions are most effective in supporting female employment. Given developments in Dutch childcare policy over the period under study, the analysis examines important policy considerations, especially the need to identify and address childcare deserts.

The relationship between childcare supply and female employment is a pressing policy issue in many developed countries. Central to this discussion is disentangling causal relationships between the form, quality, affordability, and accessibility of childcare and the quantity and quality of female employment. Elements of this discussion are further elaborated in, for instance, Chapter 11 by Hook and Li, Chapter 7 by Javornik and Yerkes, Chapter 8 by Vandenbroeck, and Chapter 24 by Sirén, Doctrinal, Van Lancker, and

\section{T. Emery $(\varangle)$}

Erasmus University Rotterdam, Rotterdam, The Netherlands e-mail: tom@odissei-data.nl 
Nieuwenhuis, all in this volume. There have been numerous studies examining the geographical distribution of childcare provision that have illustrated that it is almost never uniform, with clusters of high provision in urban, high income areas (Hank \& Kreyenfeld, 2003; Van Ham \& Mulder, 2005). Provision tends to be greatest in areas where the female employment rate could be said to be high for other reasons such as greater general prosperity, more job opportunities, and families selecting into areas with good childcare provision when they want to work (Dickens, Wollny, \& Ireland, 2012; Holloway, 1998). Most analyses are also conducted on an aggregate small area basis given that individual level data is not available and this therefore risks conclusions based on ecological fallacies (Asai, Kambayashi, \& Yamaguchi, 2015).

In this chapter we aim to utilize the unique features of the Netherlands Kinship Panel Study (NKPS) and Dutch Administrative Data on childcare facilities to examine whether the availability and type of childcare facilities in an individual's immediate vicinity are associated with mothers' labor market activity (employment type and hours worked). The Netherlands is a relatively homogenous country with high population density. Even still, the level of childcare provision is variable between locations as childcare centers are operated by private companies and the density of childcare providers reflects this. Furthermore, Dutch childcare is dominated by two forms of childcare: kinderdagverblijf (childcare centers) and gastouders (childminders). These options can be used in combination with each other or in isolation. Both are subsidized by the Dutch Government at a rate that is dependent on the parents' income. Childminders are widespread and pervasive as they are small and relatively easy to establish. Childcare centers are, however, larger operations and tend to be more variable in their provision. The options open to parents are therefore shaped by the availability of both forms of care.

This market-driven approach to provision risks geospatial and structural inequalities in access to childcare that potentially have consequences for female employment and other policy aims. These geospatial and structural inequalities in access to childcare are, however, tightly intertwined with other structural and geospatial inequalities such as poverty, a lack of employment opportunities, housing affordability, or many other factors. This makes any causal assessment exceptionally difficult and is a common feature of geospatial, sub-regional level analyses.

The longitudinal nature of the NKPS data, which has been collected over four waves between 2005 and 2014, allows us to take many of these selection effects into account and employ more robust within-individual estimates of maternal labor market activity. Through a series of models, we examine a variety of factors which may shape and determine the decision of a mother 
to work and the level of work she chooses to undertake. These include the geographic proximity of family and support networks, the local availability of jobs ascertained through low level employment data, and local small area demographics (i.e. age and ethnicity profile of the neighborhood).

The results provide a rich insight into the labor market decisions of women in the Netherlands. The findings illustrate the strong association between the geographical availability of childcare and the ability of women to work longer hours. However, more informal forms of childcare support such as childminders or family networks are not directly associated with a return to employment. These conclusions illustrate the vital role that childcare provision plays in enabling women to work a greater number of hours on the labor market.

\section{Existing Research}

Existing research on the association between childcare and female employment has centered on two dimensions of childcare availability; price and the number of places available. The ability of childcare to support maternal employment is of course heavily dependent upon the net cost of formal childcare. Studies have focused on quasi-experimental methods such as difference in difference models. For example, Havnes and Mogstad (2011) utilized an expansion of subsidies in Norwegian childcare to examine the impact of individuals' employment levels. Their findings appear to show that there is little to no impact on employment suggesting that previous research using aggregated data failed to taken into account potential ecological fallacies, omitted variables, and selection effects (Jaumotte, 2005). Using a similar design in Sweden, it was also found that the effect of a drop-in price was zero (Lundin, Mörk, \& Öckbert, 2008). In the Netherlands, the Dutch government's assessment of the introduction of subsidies in the Netherlands in 2005 using a difference in difference analysis, also indicated only a modest increase in female employment of around 3 percentage points (Bettendorf, Jongen, \& Muller, 2011). Studies from Australia (Rammohan \& Whelan, 2006), Finland (Viitanen, 2011) and the UK (Viitanen, 2005) have also shown at best modest impacts of the effect of price on female employment.

This provides a pessimistic picture regarding the role of childcare in supporting female employment. Yet, basic rational choice models of labor market participation suggest that affordable childcare is a key part of a broader family friendly policy package to support female employment (Blau $\&$ Kahn, 2013). To better understand the modest findings of existing research 
on childcare and female employment, it might be necessary to consider additional dimensions of childcare provision that may affect the ability of women to participate on the labor market. There are a number of studies that have attempted to do this, but data limitations are a considerable problem for such questions.

Van Ham and Mulder (2005) found that in the Netherlands, the probability of a woman being employed increased with the number of slots available in childcare facilities in their immediate area. The findings were able to utilize a very local level of data but are still limited by potential endogeneity surrounding individuals housing decisions and the potential for omitted variable bias at the small area level. In Germany, Hank and Kreyenfeld (2003) use regional data on child care provision but this showed no association with the probability for women to be engaged on the labor market. The study was however limited by the detail of data available to them and size of the geographical units being employed. In Japan, Asai et al. (2015) use small area estimates for municipalities and employ fixed effects using longitudinal data from 1990 to 2010 but show that there is again no effect of childcare provision at the municipal level. They reason that this merely reflects that informal childcare is a perfect substitute for formal childcare and thus the impact of public childcare provision is minimal.

In addition to studies of childcare provision, there is also an extensive literature on childcare substitutes, especially the availability of grandparental childcare. Posadas and Vidal-Fernandez (2013) found that in the United States the availability of grandparental childcare increased the female employment rate by up to 9 percentage points. This is also supported by findings in Europe which have suggested that grandparental childcare support can greatly increase the likelihood of maternal employment (Hank \& Buber, 2009). These empirical findings regularly argue that these effects are attributable to the flexibility and support offered by grandparental care provision, intermating that flexibility is a key element in resolving work and family conflicts which prevent women from working for longer hours during their child's early years (Sarti, 2010; Wheelock \& Jones, 2002). Also of interest within the context of this chapter is the persistent finding that childcare provision by grandparents is itself highly dependent on the physical proximity of the grandparent, representing a geographical constraint on employment of the mother (Zamberletti, Cavrini, \& Tomassini, 2018).

Existing studies are of course hamstrung by data limitations, and the increasing availability of geographic data and longitudinal survey data is greatly improving the capacity of social scientists to provide more acute insights into individuals' circumstances. This is especially the case when we 
consider that finding childcare arrangements that enable higher levels of employment involves a complex set of factors including the availability of auxiliary support such as grandparents and the availability of work. In this paper, we go down beyond small area estimates to provide an individual's unique position within a broader childcare context. By utilizing geocoded data on childcare facilities in the Netherlands it is possible to estimate the precise proximity of individuals to various childcare facilities and examine what specific dimensions are most important in determining the level of women's engagement on the labor market.

\section{The Context in the Netherlands}

During the 1980s and early 1990s the employment rate in the Netherlands grew considerably above the pace of other OECD countries in what came to be known as the 'Dutch Miracle' (Visser \& Hemerijck, 1999). However, the expansion in employment and particularly in female employment was largely driven by an increase in part-time work (see Fig. 20.1).

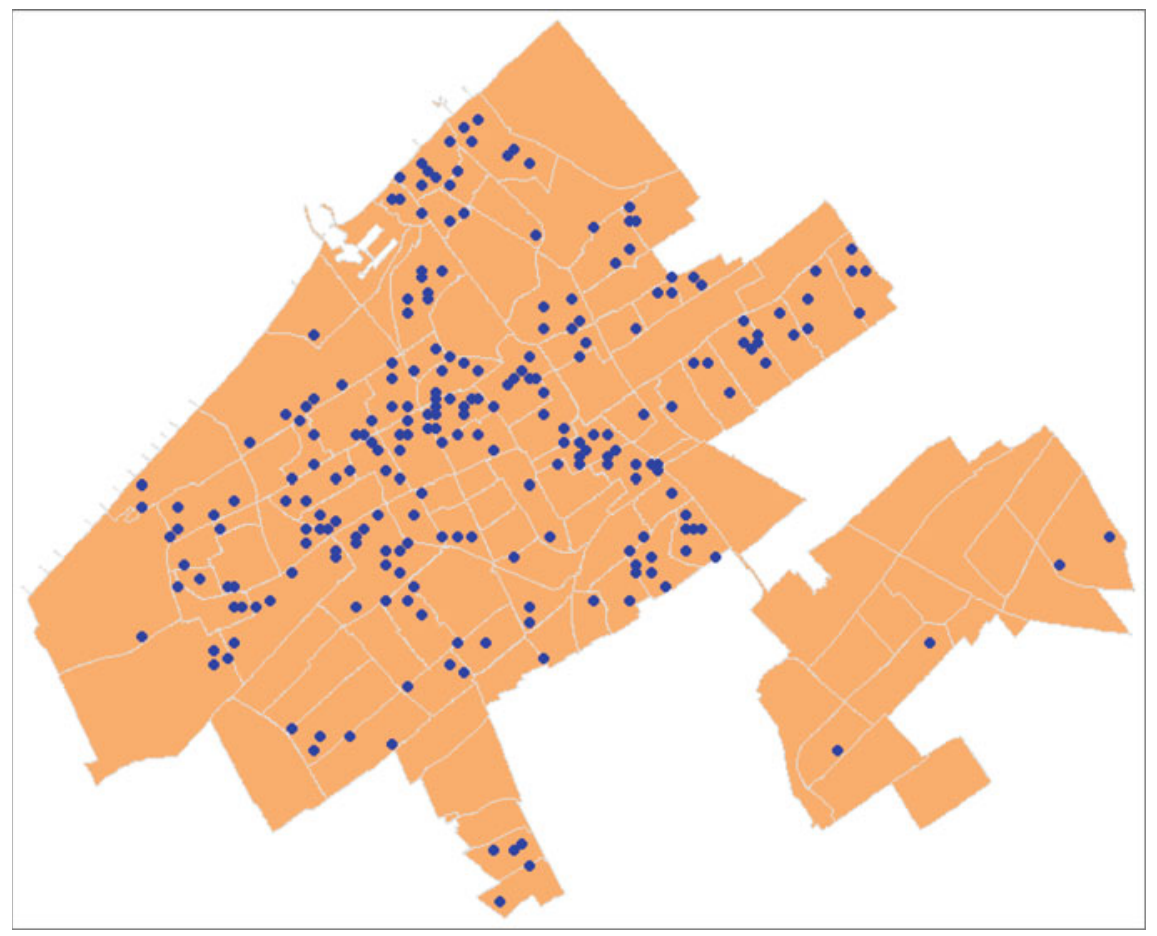

Fig. 20.1 NKPS respondents in Den Haag $(N=241)$ 
This trend has continued and the Netherlands now has the highest rates of part-time employment in the OECD. The large number of part-time workers has been recognized as a 'One and a half worker' model in which a large number of couples operate half way between the traditional breadwinner model and a full adult worker model (Lewis, Knijn, Martin, \& Ostner, 2008). This is usually represented by men working $1-0.8 \mathrm{fte}$ and women working 0.4-0.6fte. Key to this arrangement is flexibility on the part of employee, employer, and the state in ensuring that the balance is carefully managed and facilitated, an approach characteristic of the Dutch model (Fokkema, de Valk, de Beer, \& van Duin, 2008; Woldendorp, 2005).

The parental leave system in the Netherlands is an example of this flexibility as leave entitlements are specified in hours rather than days and can be used in any configuration as long as it is agreed upon by the employer and employee (Den Dulk, 2016). This flexibility enables both men and women to take parental leave as an afternoon per week, or a day per week over a much longer period of time rather than as either a single chunk or series of blocks. The replacement rate for such parental leave varies depending on which collective agreement the employee is subject to, and although a significant minority have no paid parental leave provided for within their collective agreement, the replacement rate generally varies between 50 and $75 \%$ of an individuals' average salary. The result of this is that women choosing to only work 3-4 days per week can do so for the first few years of a child's life with only limited financial impact. However, despite this policy being gender neutral, parental leave usage among men is much lower (Keizer, 2015).

With regards to childcare, the emphasis in the Netherlands is also on supporting employment while simultaneously allowing for flexible arrangements. The first Childcare act was introduced in on 1 January 2005, coinciding with wave 1 of the NKPS. This has led to a significant shift in childcare provision over the period of study (Fokkema et al., 2008). The 2005 act prohibited municipalities from providing childcare directly and eliminated subsidies from municipalities and employers. Instead, a subsidy would be provided directly by the central government to parents which was to be used to pay for childcare from approved commercial or non-profit providers (Knijn \& Lewis, 2017). In 2004, before the act was introduced, just 30\% of all childcare facilities were run by private organizations, with the majority of the remaining facilities operated by local authorities, but this had risen to $70 \%$ by 2010 (Bettendorf et al., 2011).

There are two primary forms of formal childcare for children aged 0-4 provisioned for in the Childcare act which are childcare centers and childminders. Childminders often provide more specific needs but are commonly 
single individuals who are willing to provide childcare from their own home and are unattached to specific institutions. Childcare centers vary in size but generally have around 40-70 places. They have fixed opening hours which generally last from 7:30 (a.m.) through to 18:30 (6:30 p.m.). Unlike with parental leave, childcare centers charge only with regards to days and do not allow for reductions in costs if children do not spend the full day in the childcare center. This limits the flexibility in combining childcare with parttime work. According to data from the Ministry of Social Affairs, the number of childcare centers has risen from approximately 3464 in 2010 to 6025 in $2015 .{ }^{1}$ As of 2015 , there are approximately 35,000 registered childminders. Therefore, while childminders are greater in number, childcare centers serve approximately 10 times the number of children.

The costs of childcare are subsidized regardless of whether an individual uses a childcare center or child minder. The average cost of childcare is around $€ 1800$ per month for care of five days a week. The subsidies are highly dependent upon the joint income of both parents with the average subsidy covering around $40-60 \%$ of childcare costs. Net Childcare costs represent around $10.1 \%$ of family net income compared with the OECD average of $11.8 \%$ and contrasting with 26.6 and $23.1 \%$ found in the UK and US respectively. Given this, the childcare facilities in the Netherlands are relatively cheap and flexible in supporting working parents. However, see Chapter 13 by Maldonado and Nieuwenhuis in this Volume to have similar numbers differentiated by twoparent and single-parent families. An additional feature of the Netherlands childcare market however is the range of choice available to parents in the local area. The average distance to a childcare center is now less than $3 \mathrm{~km}$ and the average distance to a child minder is just $250 \mathrm{~m}$. This means that the average Dutch household is just a 4-minute drive from their nearest childcare center or about a 10-minute cycle.

It is possible that this diverse range of options open to Dutch Parents facilitates their work-life balance and enables greater female employment. It should be noted that the childcare provision referred to here is purely with reference to children aged $0-4$. At the age of 4, children are eligible to attend the public school system. However, given that public school opening hours are more restricted than those of childcare facilities, there is a need for childcare beyond the age of 4 . This is addressed through the provision of after school care (Buitenschoolse Opvang, BSO). BSO facilities are sometimes integrated within childcare centers but can also be provided by the local school or a

\footnotetext{
${ }^{1}$ www.landelijkregisterkinderopvang.nl.
} 
further organization. Therefore, if a parent has children aged 0-4 and children aged $4+$, it is necessary to ensure that all children have care provision for the whole day.

\section{Hypotheses}

In this paper we seek to move beyond a cost-benefit analysis of childcare and female employment and instead adopt a geospatial perspective focused on the access to childcare options. Rather than the decision to work being guided by a pocket book analysis of returns to employment versus the costs of childcare, we posit that the decision as to whether to work is largely driven by practical constraints associated with the proximity and flexibility of childcare. The subsidies within Dutch childcare do not eliminate the costs of childcare but they are designed such that work is always fiscally positive (i.e. the cost of childcare per hour is less than the hourly wage). Under this system, marginal returns on working an additional hour are still variable and particularly across different income groups. However, this does suggest that cost-benefit assessments are not the primary constraint on work decisions.

Instead we choose to focus on the availability, proximity, and diversity of childcare options available. This approach assumes that, given the persistent positive returns to working additional hours, women will seek to work $0.4-$ $08 \mathrm{fte}$. The decision to not work full-time or something approaching full-time is due to constraints on childcare availability to enable this, as well as the availability of parental leave. Women faced with the decision of how much to work will first seek to make use of their parental leave entitlements. Spread over four years, these entitlements roughly translate to one day per week in which a parent can stay home and care for the child without incurring a significant financial loss. Beyond this, we assume that women will seek to work a 32-hour week and that the primary constraint on this is availability of childcare. Regarding the availability of childcare, there are two ways to view this availability; in proximity to their work or in proximity to their home. We opt for proximity to their home for several reasons. Firstly, while women take on a disproportionate responsibility for childcare, most couples seek a childcare placement near their home rather than place of employment as it at least makes practical the possibility that the male partner can also drop off and pick up the child (Doan \& Quadlin, 2019). Secondly, we assume that couples tend to opt for childcare close to their home than work as a move of address is less likely than a move in employment and couples will 
seek to limit disruption to their childcare arrangements (Langford, Higgs, \& Dallimore, 2019). Finally, the assumption of a fixed place of work is often misplaced, making it hard to determine an appropriate childhood location. This is borne out by the NKPS data which provides vague or missing data on the location of many places of employment.

This paper tests the theory that geospatial availability of childcare relative to a women's residence determines their employment hours by using the following three hypotheses:

H1 The closer a woman is to a childcare facility (either childcare center or childminder), the more hours she will work each week.

This hypothesis examines the straight forward idea that physical proximity enables parents and women specifically to better coordinate work and family life and ensure that they are able to work more.

H2 The more childcare facilities a woman has in $1 \mathrm{~km}$ radius, the more hours she will work each week.

This hypothesis examines whether it is density and not merely proximity which aides employment by increasing the number of options available to a woman in negotiating her work-life balance.

H3 The more types of childcare facilities (either childcare center or childminder) a woman has in a $1 \mathrm{~km}$ radius, the more hours she will work each week.

This expands on the second hypothesis by suggesting it is not the density of childcare facilities but also the range. If true, an individual with many childcare centers and childminders in their immediate proximity would be the most likely to work longer hours as they can utilize both forms of childcare to best match their needs. Throughout the analysis we also test for the types of childcare independently of each other, recognizing that they support maternal employment in distinct ways. This analysis therefore seeks to gage the impact of the expansion in Dutch Childcare since 2005 at the sub-regional level and explore the geospatial determinants of female employment that it potentially implies. 


\section{Data \& Methods}

\section{The Netherlands Kinship Panel Study (NKPS)}

The data in this analysis are provided by the Netherlands Kinship Panel Study (www.nkps.nl). The NKPS is a panel study on family dynamics in the Netherlands that as of 2014 has collected four waves of data on individuals and their kin. The NKPS covers the population aged 18-79 in the baseline year of 2005 and who were resident in the Netherlands. The research questions revolve around the theme of solidarity, which is defined as 'feelings of mutual affinity in family relationships', and how these are expressed in behavioral terms. The NKPS has four special features that make it highly innovative: it is large ( $N=9500$ at Wave 1), it is a panel (prospective longitudinal design), it is multi-method (the data collection involves both structured interviews and in-depth open interviews), and it is multi-actor (the data are from individual respondents as well as from family members).

The sample for this analysis was limited to women of childbearing age (18-40 in 2005) who were then followed over the next nine years and reinterviewed every three years $(2008,2011,2014)$. From these interviews, it is possible to follow employment and fertility histories of these women over the 9 years covered by the study. Only women who responded in all four waves of the study were included in the analysis yielding a total analytic sample of 604 women and 2416 observations. The attrition in the study was $68.36 \%$ between wave 1 and wave 4 which indicates high potential for selectivity bias within the analysis. For example, in the target sample at wave 1 the percentage of individuals with higher education is $36 \%$ but once those who do not participate in all four waves are excluded, this rises to $44 \%$ indicating higher attrition among lower educated groups.

The main dependent variable within the study is the number of hours worked per week in the last 6 months. This is reported in each wave of the NKPS and refers to the 6 months prior to interview. The average is 23 hours per week, inclusive of those not working. This rises to 27 hours per week when those who do not work are excluded. In addition to the independent variables which are detailed as part of the contextual data below, several controls are included below based on previous research. These include the number of children the respondent has, the marital status of the respondent at the time of interview (i.e. single, cohabiting or married), the educational level of the respondent at interview (Low: ISCED 0-2; Medium: ISCED 34; High: ISCED 5-7) and the distance in kilometers to the nearest parent or 
Table 20.1 Descriptive statistics

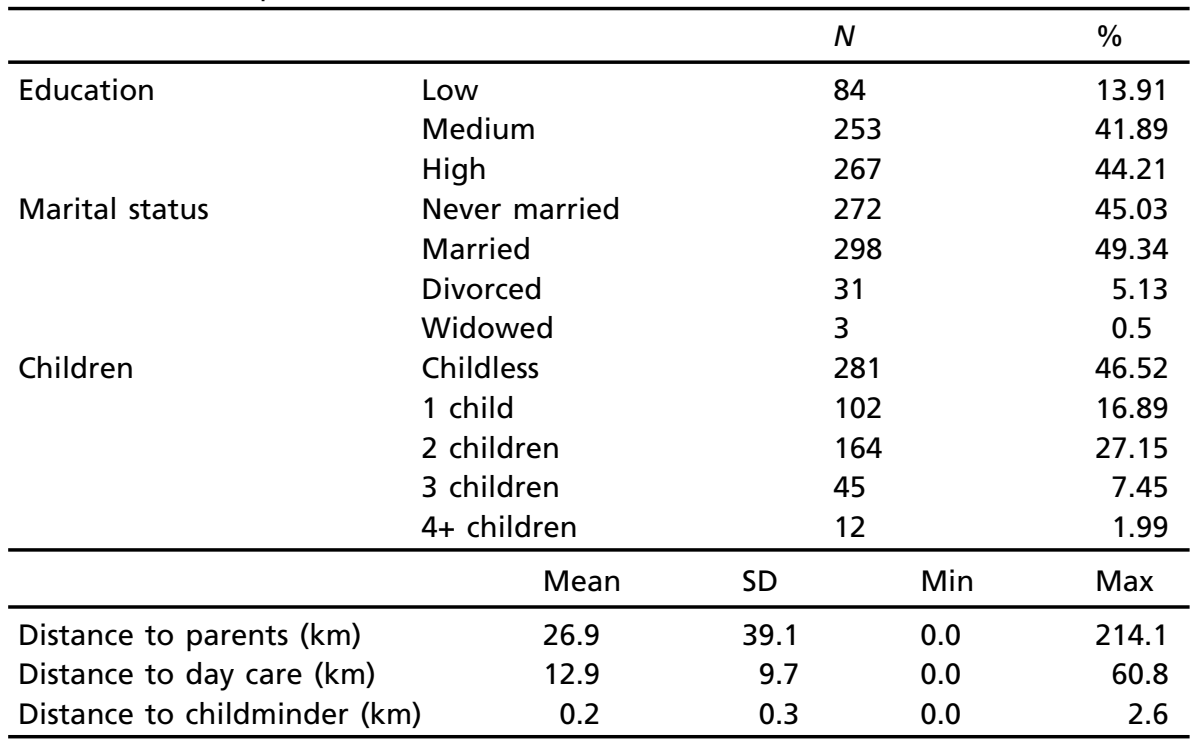

parent-in-law at the time of interview. Descriptive statistics are presented in Table 20.1.

The NKPS provides highly detailed data on the respondents' geography including geo-coding of their address, their parents' address, their work address, their partners work address, and their closest friends address. This ensures that respondents can be placed within a highly accurate geographical context in relation to other geographic sources of data in the Netherlands. To illustrate the degree of detail this provides, Fig. 20.1 shows respondents in the city of Den Haag (population: 510,909). The gray lines represent the demarcations of neighborhoods (buurten).

\section{Contextual Data}

To enrich the data provided by the NKPS, the Landelijk Register Kinderopvang en Peuterspeelzalen (Register for Childcare and Toddler Groups) was used. This register is the official register for all childcare providers in the Netherlands and is publicly accessible at (www.landelijkregisterkinderopva ng.nl). The postal codes of all facilities are provided as part of the register and can therefore be geolocated to their exact location. Upon request this dataset can also be accessed in historic form by which dates of registering and deregistering of childcare facilities can be accessed. This therefore provides a record of all childcare facilities and their geographic location for the period 
of the study between 2005 and 2015, including facilities that open and close between these dates and the months in which they do so. Using this information, it is possible to calculate childcare availability for each respondent in the NKPS via a number of metrics. The register also demarcates childcare facilities by types. This allows for type specific metrics to also be calculated. To demonstrate the richness of this data, Fig. 20.2 shows the childcare centers registered in Den Haag in 2010.

Figure 20.3 also illustrates the shift in the mean distance between a member of our analytical sample and a private day care center over the four waves of the NKPS. The results illustrate that in 2005, when the legislation had only recently come into force and private sector providers were scarce, the average distance to a private childcare provider was around $13 \mathrm{~km}$. Over the years the number of childcare providers has increased considerably, and the expansion has reduced not only the median but also eradicated large outliers resulting in average distance of just $750 \mathrm{~m}$ and an observed maximum of just $7 \mathrm{~km}$. These figures show the changing nature of childcare availability over the period of study.

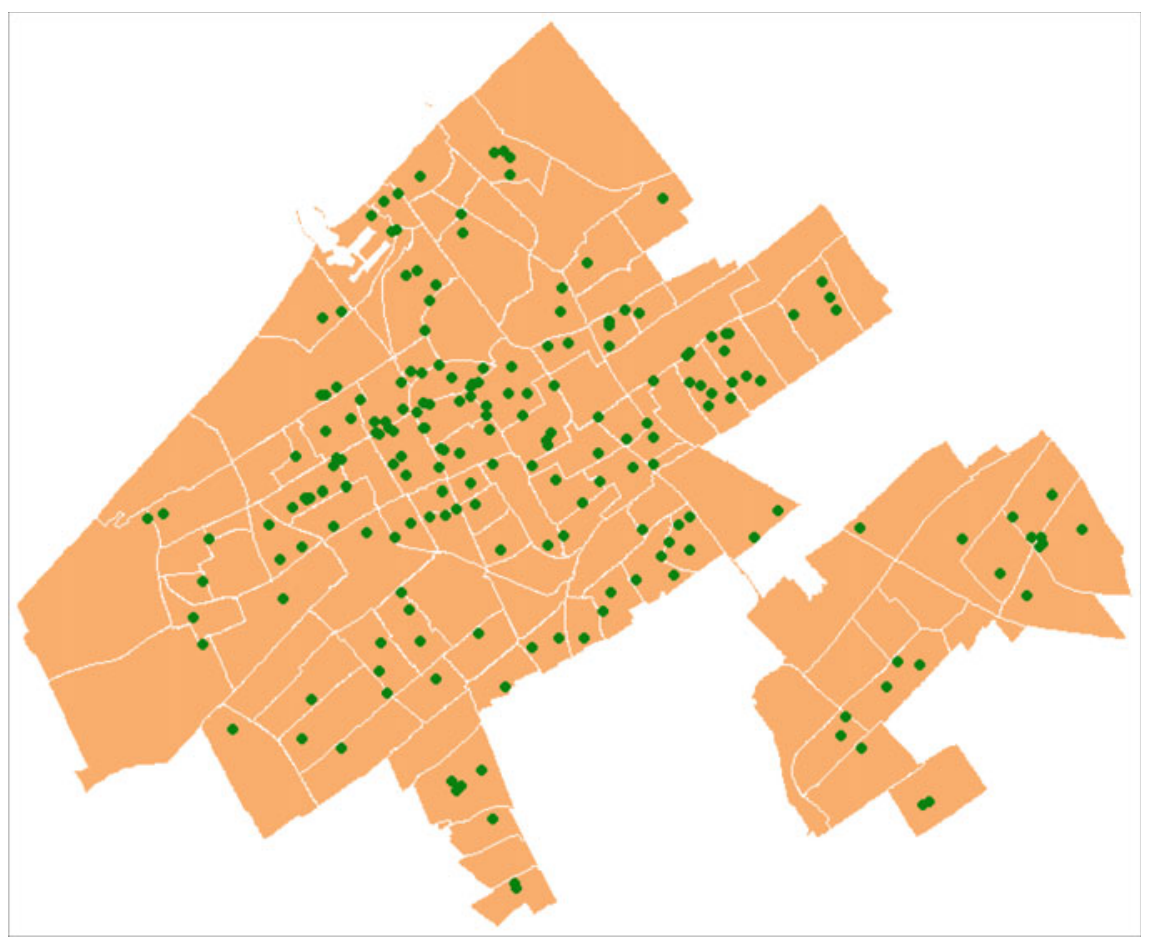

Fig. 20.2 Nurseries in Den Haag in 2010 (Source www.landelijkregisterkinderopva ng.nl) 


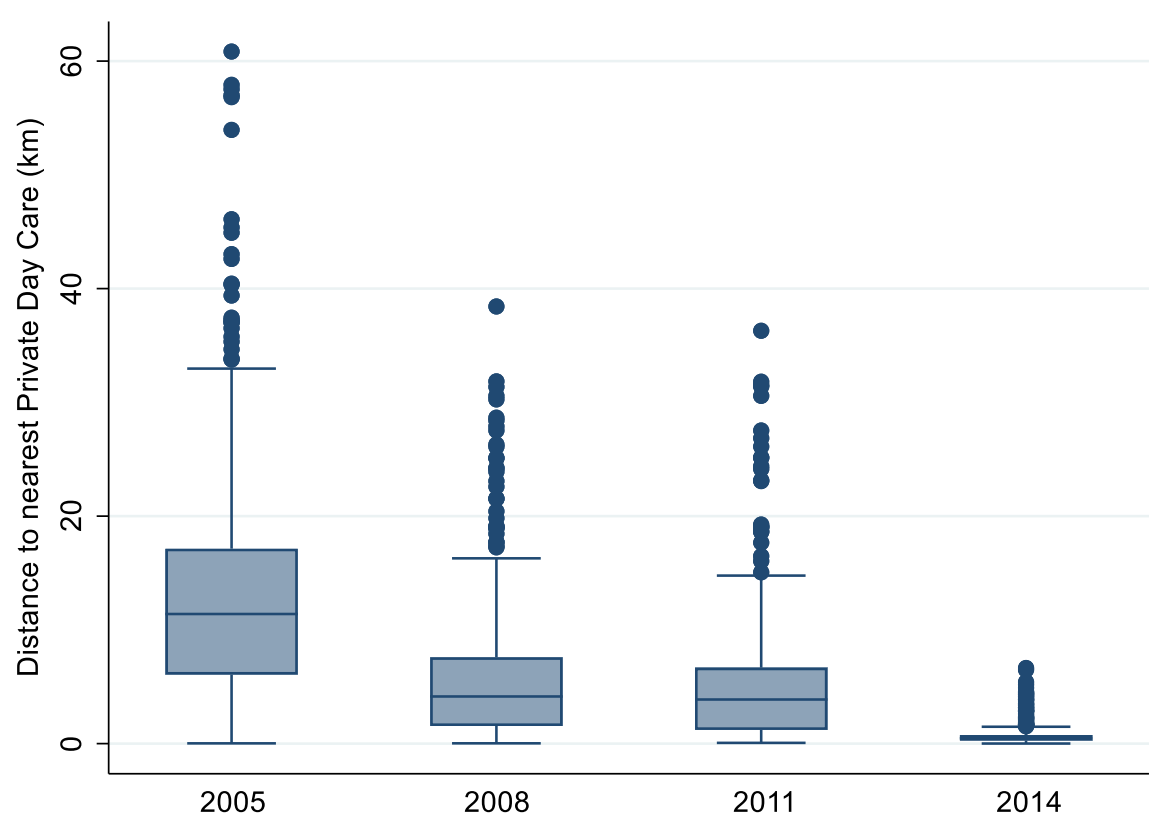

Fig. 20.3 Distance to nearest private childcare provider, by wave

In addition to data from the NKPS and childcare registries, we use data from $\mathrm{CBS}^{2}$ on small area measures of economic prosperity and growth that will inevitably shape a woman's labor market activity. This includes both measures of unemployment, average house prices and demographic composition of the local area. These measures are available at the level of gemeente (community) which normally consist of between 5 and 10 neighborhoods (buurten).

\section{Analytical Framework}

The analysis is multilevel in nature with 2416 observations nested in 604 respondents. These are clustered in communities to produce robust standard errors. The dependent variables were derived from the respondents in the NKPS at the person-wave level and reflected the number of hours worked. The number of hours worked is then estimated using a multilevel tobit model with two levels (i.e. person-month, person). The multilevel tobit structures the analysis such that whether the respondent works is first estimated

\footnotetext{
${ }^{2}$ Centraal Bureau voor Statistiek/Statistics Netherlands-The Dutch Statistical Office.
} 
(i.e. hours worked $>0$ ) and then the number of hours are estimated using a weighted OLS (Amemiya, 1984).

The independent variables are those associated with the proximity and density of childcare facilities that are derived from the contextual data. These are variable at the level of person-wave given that the facilities in someone's proximity changes over time and individuals move. It is also important to note that the proximity of childcare facilities is independent of the neighborhood and municipality boundaries with all values calculated for each respondent, providing a unique value on all independent variables. Three models are presented as part of the analysis. First the proximity of the closest childcare facility is included in order to ascertain whether it is crude proximity that is associated with female employment. Second, the number of each specific facility within $1 \mathrm{~km}$ is used as an independent variable with the proximity variable in the first analysis omitted. This is to measure the impact of density of each form on female employment. Finally, an interaction term is introduced to extend the second model between types of childcare facilities in order to test the possibility that diversity in facilities influences female employment.

\section{Results}

The results are presented in Table 20.2, and are broadly in line with findings from the existing literature on female employment patterns (Hank \& Kreyenfeld, 2003; Van Ham \& Mulder, 2005). Education is positively associated with working more hours per week, with those with higher education working a full 10 hours longer than those with lower education. In terms of marital status, we see that divorced individuals work longer hours than those who have never been married or those who are married. Children have a steep negative impact on the number of hours worked per week. If they do work, those with one child will work around 8 hours (one working day) less per week than those who are childless. Those with two or three children work between 11 and 12 hours less and those with four or more children work around 18 hours less. Controls for wave and age were also included but they did not exhibit significant effects or affect the results of the other variables reported. 
Table 20.2 Results of tobit models 1-3

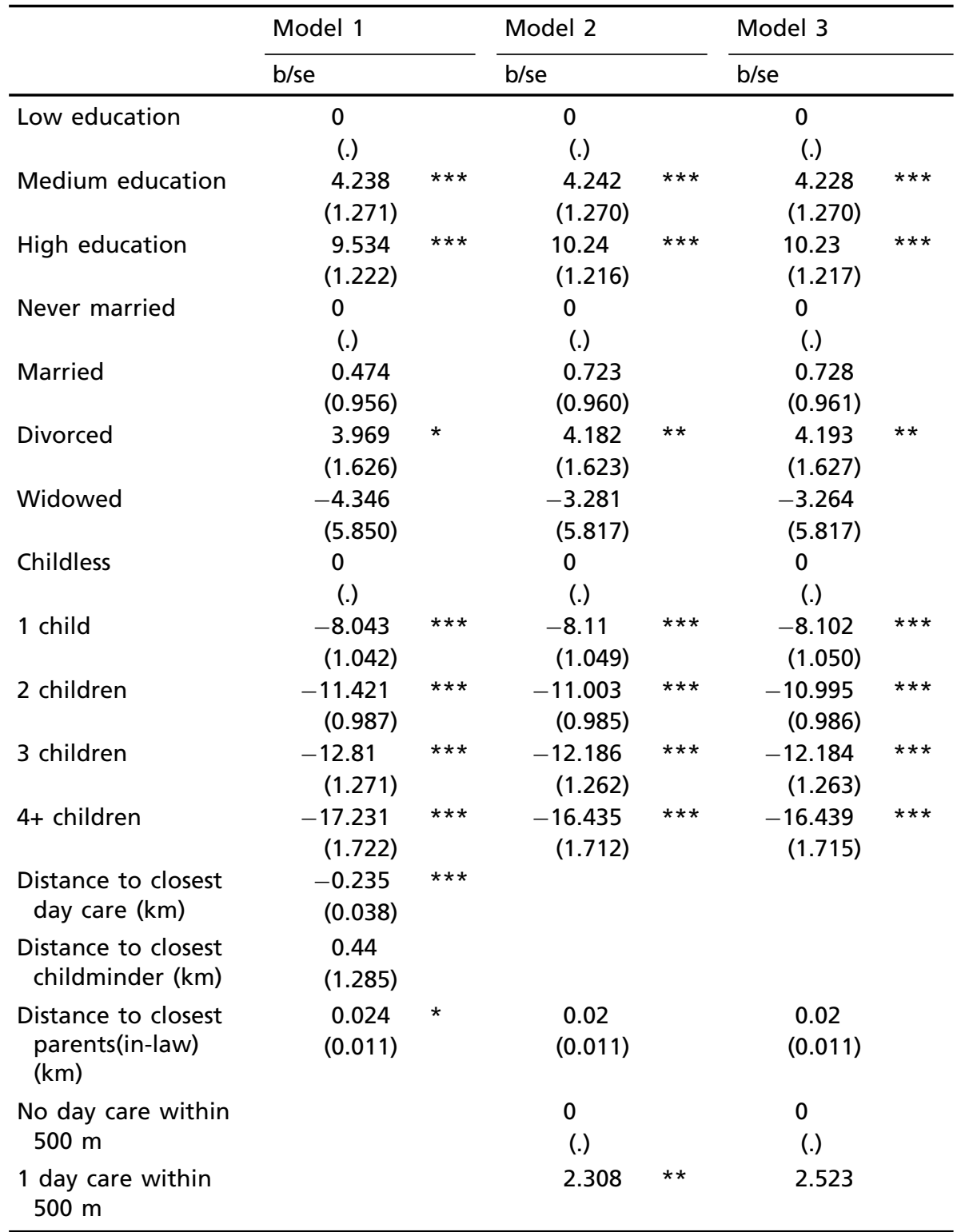


Table 20.2 (continued)

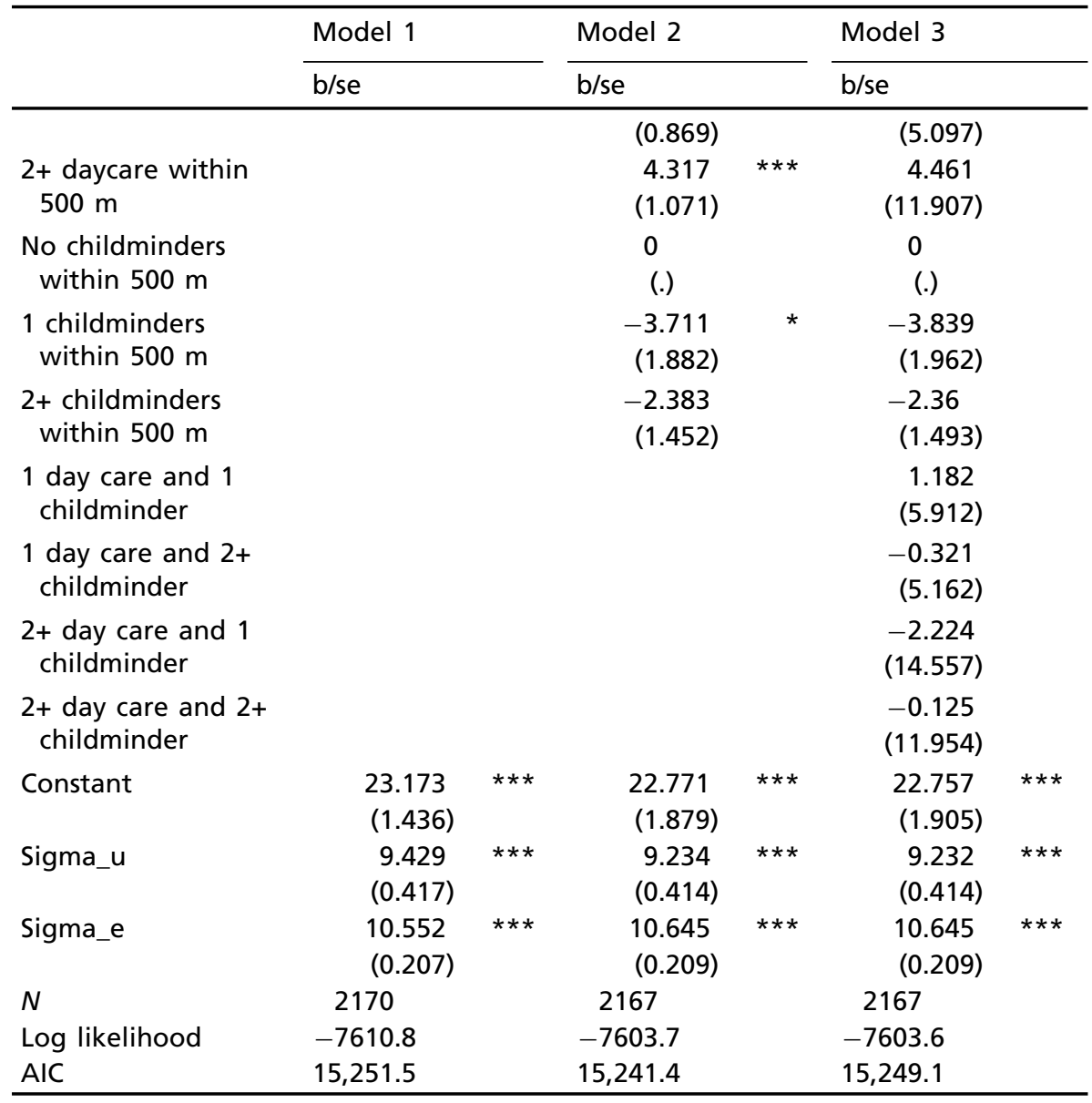

${ }^{*}=p<0.05,{ }^{* *}=p<0.01,{ }^{* * *}=p<0.001$

Regarding the first model the results show that the relationship between distance and the number of working hours is negative as hypothesized. For each additional kilometer that the childcare is from the respondents' address, an employed respondent works around 15 minutes less per week. This relationship is strongly significant. The 5 and $95 \%$ ranges of the distance to a childcare facility are $0 \mathrm{~km}$ and $20 \mathrm{~km}$, respectively, which suggests a maximal effect size of around 5 hours per week. Another way to consider this given the trends observed across the Netherlands during this period is to consider the difference in the average distance to childcare in 2005 and 2014. This fell from $12 \mathrm{~km}$ to just $750 \mathrm{~m}$ which, according to these results would have resulted in an increase of around 3 hours per week in work for those in 
employment. Ordinal measures of distance were tested (not shown) but similarly showed a linear relationship between proximity and employment. Given this, the parsimonious linear model was preferred.

The distance to the nearest childminder is not significant. The distance to parents or parents-in-law who might offer an alternative form of childcare was significant and positive, but the effect-size was very small and represents just 30 minutes more work every month for every additional kilometer they are further away. It disappears entirely when the density and variety of childcare facilities are added to the model, emphasizing the limited role that the proximity of grandparental care has in shaping female employment in the Netherlands. The positive association could be related to a selection effect by which individuals who live further away from their parents, do so because they moved for improved employment prospects. Moves made within the period of study are controlled for through the fixed effects design but this doesn't fully capture the potential long-term decisions of individuals to move away to university or urban centers in pursuit of work, and simultaneously areas with better childcare provision.

In model 2 we tested the hypothesis that density was a better estimator of the number of hours worked than simply recording the proximity. The results indicate that the number of hours worked are around 4 hours more when there are 2 or more childcare facilities within $500 \mathrm{~m}$ of an individual's home. This may seem like an unrealistic density for childcare facilities, yet in wave 4 of the NKPS $25 \%$ of respondents in our analytical sample benefited from such density. This finding holds true even though we are controlling for population density and employment rates at the municipality level and clustering the standard errors.

The number of childminders within $500 \mathrm{~m}$ is negatively associated with the number of hours worked, though the standard errors are large and only significant at the $95 \%$ level. The reason for this is because $85 \%$ of the sample have at least 2 childminders within $500 \mathrm{~m}$ and $93 \%$ have at least one. This means that the reference category in this group is relatively atypical and small and this may lead to the strange result. The difference between 1 and $2+$ is, however, not statistically significant. We recoded and recast this variable in a number of ways with various intervals to reflect the distinct distribution, but none showed a significant and consistent effect in any direction of the density of childminders on working hours.

The third model presents an interaction term between the density of the childminders and the day care centers, but the results were not significant. We also ran an interaction term to see if the effect of day care centers varied across educational groups or parity but there were no significant effects. When 
looking at the model fit statistics, it appears as though density of day care centers are a marginally better model fit, despite a restricted categorization that is used. This supports the second hypothesis that it is density rather than strict proximity that better explains the number of hours worked by women.

\section{Conclusion}

This chapter sought to examine the way in which the geographic availability of childcare at a sub-regional and highly localized level. Since 2005, the Netherlands has seen a rapid expansion in the number and geographic spread of childcare centers and this offered a natural experiment in the shaping of women's decisions to work longer hours. This contrasts strongly with much of the existing literature which has focused on an economic and cost focused analysis of childcares effect on female employment (Rammohan \& Whelan, 2006; Viitanen, 2005, 2011). Research on family support and grandparenting has, however, illustrated that availability, proximity, and flexibility are crucial factors in determining childcare efficacy with regards to female employment.

The results provide strong evidence that in the Netherlands, the increased geographic availability of childcare increased the number of hours a woman works. This effect is consistent across educational groups and the results suggest that increased geographic availability could increase a woman's working week by up to 4 hours. This may appear a small effect but would represent 2 additional days' work per month, a 15\% increase on the average number of hours worked by women aged $18-35$ in 2015 . Whether assessing the proximity of childcare or the density of childcare providers, there was a clear positive effect on working hours. From our results, it is also clear that childminders (i.e. small, independent childcare providers) are not positively associated with employed women working longer hours. They were also not seen to affect the efficacy of day care centers by providing diverse choice.

The results here were possible due to highly innovative data collection within the NKPS that allows for analysis of individuals' geospatial context. This perspective is highly valuable in providing greater detail on people's immediate surroundings and differentiating between their lived experiences of policies and the world in which they are embedded. However, the analysis here can be extended in many different directions to offer greater detail and insight into these policy issues at a sub-regional basis. Many social surveys and data facilities are making geospatial analysis possible and this opens up a new range of possibilities for the analysis of policy at a sub-regional level. Secure remote access environments, distributed computing, and the general 
data protection regulation provide an increasingly practical framework for collecting analyzing this kind of geospatial data.

In this instance, disclosure issues were managed by restricting access to the original data collecting institutes and thus ensuring that it was only used for research purposes (Article 9.2(j) of the GDPR). Outputs such as Fig. 20.1 were then assessed for their disclosure risk which was deemed minimal given that (a) respondents' location was masked by a random error term extending up to $100 \mathrm{~m}$ and (b) by not displaying covariates in a geospatial distribution. Social scientists and policy analysts must be increasingly open and engage with geospatial sciences to best exploit the potential of such methodologies and their ability to provide key and direct policy insights. The data used in the analysis here was used to identify several neighborhoods in the Netherlands where childcare accessibility was below that expected of an area with given density and income levels. Identifying such childcare deserts is a potentially important tool for policy makers.

This chapter struggled to fully capture potential confounding and selection effects at a geo-spatial level, and this could be much improved not only through further analysis in this area but also through the development of research in the field of geospatial policy analysis. Having said that, shortterm selection effects during the twelve-year study period are captured and controlled for and only long-term selection effects remain. Furthermore, the main shift in individuals' exposure to childcare facilities came from rapid expansion in childcare provision rather than from personal moves into areas with better childcare. In wave 1, those living in an area within the top $20 \%$ of childcare provision would have been in the bottom $20 \%$ by wave 4 . The variance in the main independent variable is therefore temporal and not associated with any personal decisions or characteristics. It is unlikely that the effects presented here are attributable to a further geographical feature that is correlated with both female working hours and day care centers or that it is a selection effect by which those who want to work longer move to the places with better childcare. To further address longer term selection effects however, it would be necessary to apply an instrumental variable approach or construct a natural experiment but these lay outside the scope of this chapter.

The potential for such analysis with regards to policy is considerable. The more fine-grained results within this analysis allow for the identification of childcare deserts and precise and explicit policy advice to policy makers at a highly localized level. Precise estimates of geo-spatial contexts translate directly into more precise policy interventions and a shorter line between research and policy makers. 


\section{References}

Amemiya, T. (1984). Tobit models: A survey. Journal of Econometrics, 24(1-2), 361. https://doi.org/10.1016/0304-4076(84)90074-5.

Asai, Y., Kambayashi, R., \& Yamaguchi, S. (2015). Childcare availability, household structure, and maternal employment. Journal of the Japanese and International Economies, 38, 172-192. https://doi.org/10.1016/j.jjie.2015.05.009.

Bettendorf, L. J. H., Jongen, E. L. W., \& Muller, P. (2011). Childcare subsidies and labour supply: Evidence from a large Dutch reform. The Hague. Retrieved from https:/www.cpb.nl/sites/default/files/publicaties/download/cpb-discussionpaper-217-childcare-subsidies-and-labour-supply.pdf.

Blau, F. D., \& Kahn, L. M. (2013). Female labor supply: Why is the United States falling behind? American Economic Review, 103(3), 251-256. https://doi.org/10. 1257/aer.103.3.251.

Den Dulk, L. (2016). The Netherlands country note: International review of leave policies and research 2016. Retrieved from http://www.leavenetwork.org/lp_and_ r_reports/.

Dickens, S., Wollny, I., \& Ireland, E. (2012). Childcare sufficiency and sustainability in disadvantaged areas. London. Retrieved from https://www.gov.uk/government/ uploads/system/uploads/attachment_data/file/219621/DFE-RB246.pdf.

Doan, L., \& Quadlin, N. (2019). Partner characteristics and perceptions of responsibility for housework and child care. Journal of Marriage and Family, 81(1), 145-163. https://doi.org/10.1111/jomf.12526.

Fokkema, T., de Valk, H., de Beer, J., \& van Duin, C. (2008). The Netherlands: Childbearing within the context of a "Poldermodel" society. Demographic Research, 19(21), 743-794. https://doi.org/10.4054/DemRes.2008.19.21.

Hank, K., \& Buber, I. (2009). Grandparents caring for their grandchildren. Journal of Family Issues, 30(1), 53-73. https://doi.org/10.1177/0192513X08322627.

Hank, K., \& Kreyenfeld, M. (2003). A multilevel analysis of child care and women's fertility decisions in Western Germany. Journal of Marriage and Family, 65(3), 584-596. https://doi.org/10.1111/j.1741-3737.2003.00584.x.

Havnes, T., \& Mogstad, M. (2011). "Money for nothing? Universal child care and maternal employment". Journal of Public Economics, 95(11-12), 1455-1465.

Holloway, S. L. (1998). Local childcare cultures: Moral geographies of mothering and the social organisation of pre-school education. Gender, Place and Culture, 5(1), 29-53. https://doi.org/10.1080/09663699825313.

Jaumotte, F. (2005). Female labour force participation: Past trends and main determinants in OECD countries large cross-country differences persist in the rate of female participation (OECD Economics Department Working Papers No. 376). https:// doi.org/10.2139/ssrn.2344556. 
Keizer, R. (2015). Which men become involved fathers? The impact of men's own attitudes on paternal involvement in the Netherlands. International Review of Sociology, 25(3), 359-372. https://doi.org/10.1080/03906701.2015.1078531.

Knijn, T., \& Lewis, J. (2017). ECEC: Childcare markets in the Netherlands and England. In B. Unger, D. van der Linde, \& M. Getzner (Eds.), Public or private goods? (pp. 150-164). Edward Elgar Publishing. Retrieved from https://books. google.co.uk/books?hl=en\&lr=\&id=_npHDgAAQBAJ\&oi=fnd\&pg=PA150\& $\mathrm{dq}=$ childcare + in + the + netherlands\&ots=zo0TYx1g0I\&sig=6vpobervLK9Y1MP WtiVxjcexm-M.

Langford, M., Higgs, G., \& Dallimore, D. J. (2019). Investigating spatial variations in access to childcare provision using network-based geographic information system models. Social Policy \& Administration, 53(5), 661-677. https://doi.org/ 10.1111/spol.12419.

Lewis, J., Knijn, T., Martin, C., \& Ostner, I. (2008). Patterns of development in work/family reconciliation policies for parents in France, Germany, the Netherlands, and the UK in the 2000s. Social Politics, 15(3), 261-286. https://doi.org/ 10.1093/sp/jxn016.

Lundin, D., Mörk, E., \& Öckbert, B. (2008). How far can reduced child care prices push female labour supply. Labour Economics, 15, 647-659. Retrieved from http://www.sciencedirect.com/science/article/pii/S0927537108000389.

Posadas, J., \& Vidal-Fernandez, M. (2013). Grandparents' childcare and female labor force participation. IZA Journal of Labor Policy, 2(1), 14. https://doi.org/ 10.1186/2193-9004-2-14.

Rammohan, A., \& Whelan, S. (2006). Child care costs and the employment status of married Australian mothers (Centre for Economic Policy Research Discussion Paper No. 517). The Australian National University. Retrieved from https:// www.researchgate.net/profile/Anu_Rammohan/publication/4905054_Child_C are_Costs_and_the_Employment_Status_of_Married_Australian_Mothers/links/ 0912f50bffc36b6c02000000.pdf.

Sarti, R. (2010). Who cares for me? Grandparents, nannies and babysitters caring for children in contemporary Italy. Paedagogica Historica, 46 (6), 789-802. https:// doi.org/10.1080/00309230.2010.526347.

Van Ham, M., \& Mulder, C. H. (2005). Geographical access to childcare and mothers' labour-force participation. Tijdschrift Voor Economische En Sociale Geografie, 96(1), 63-74. https://doi.org/10.1111/j.1467-9663.2005.00439.x.

Viitanen, T. K. (2005). Cost of childcare and female employment in the UK. Labour, 19(SUPPL. 1), 149-170. https://doi.org/10.1111/j.1467-9914.2005. 00325.x.

Viitanen, T. K. (2011). Child care voucher and labour market behaviour: Experimental evidence from Finland. Applied Economics, 43(23), 3203-3212. https:// doi.org/10.1080/00036840903508346. 
Visser, J., \& Hemerijck, A. (1999). A Dutch miracle: Job growth, welfare reform and corporatism in the Netherlands. Amsterdam University Press. Retrieved from http://pubman.mpdl.mpg.de/pubman/faces/viewItemOverviewPage.jsp?ite mId=escidoc: 2229759 .

Wheelock, J., \& Jones, K. (2002). 'Grandparents are the next best thing': Informal childcare for working parents in urban Britain. Journal of Social Policy, 31(3), 441-463. https://doi.org/10.1017/S0047279402006657.

Woldendorp, J. (2005). The Polder Model: From disease to miracle? Dutch neocorporatism 1965-2000. Thela Thesis. Retrieved from http://books.google.com/ books?hl=en\&lr=\&id=PQSCkxINmoUC\&oi=fnd\&pg=PR9\&dq=\%22Neo-cor poratism + as + a+strategy+for+conflict+regulation + in + the + Netherlands $\% 22 \& o t s=$ ZnPISnTcqM\&sig=2qSwwiLmYpQutfFJrLzilKEkh20.

Zamberletti, J., Cavrini, G., \& Tomassini, C. (2018). Grandparents providing childcare in Italy. European Journal of Ageing, 15(3), 265-275. https://doi.org/10. 1007/s10433-018-0479-y.

Open Access This chapter is licensed under the terms of the Creative Commons Attribution 4.0 International License (http://creativecommons.org/licenses/by/4.0/), which permits use, sharing, adaptation, distribution and reproduction in any medium or format, as long as you give appropriate credit to the original author(s) and the source, provide a link to the Creative Commons licence and indicate if changes were made.

The images or other third party material in this chapter are included in the chapter's Creative Commons licence, unless indicated otherwise in a credit line to the material. If material is not included in the chapter's Creative Commons licence and your intended use is not permitted by statutory regulation or exceeds the permitted use, you will need to obtain permission directly from the copyright holder. 